\title{
HIGHWAY TECHNOLOGY
}

\section{The Schmargendorf Flyover in Berlin}

T HIS is a prestressed concrete bridge with shell-like structural action of modern and somewhat novel design, of particular interest to highway engineers and technologists. It forms an important link in the express ring road in Berlin started in 1956, the first section, approximately $2 \mathrm{~km}$ in length, being opened to traffic in 1958. Going from north to south, the route of the expressway follows mainly that of the urban ring railway ('S-Bahn'). It has been designed as a dual-carriage motorway, free from grade intersections, and is the prineipal member of a planned expressway network for the city. This flyover is situated a short distance from the Mecklenburgische Strasse, just outside Schmargendorf railway station, where both carriageways of the expressway cross the railway tracks, from the outside to the inside of the ring line. Thus the flyover structure had to be $S$-shaped in plan to comply with the traffic conditions imposed. It is approximately $230 \mathrm{~m}$ long, but the viaduct connecting it to the Mecklenburgische Strasse adds another $250 \mathrm{~m}$, thus producing an elevated dual-carriage motorway nearly $500 \mathrm{~m}$ in length. Details of this project are given in an article by $\mathrm{H}$. Heusel*.

This article is not only noteworthy for the detailed description of the ultimate design of this flyover, but also for the information it contains coneerning the manner in which this structure took shape; it was the result of a competition wherein eleven selected contracting firms with experience in design and construction of prestressed concrete bridges were invited to tender. All put in their own schemes but four firms were short-listed, and the article discussos each of their proposals on their merits. The scheme finally adopted was that of Dyekerhoff and Widman K.G. and was carried into effect with relatively minor modifications. The advantage of considering so many different proposals to meet the requirements of this difficult flyover situation, the production of the 'working design' from so many drawing boards, must have been of considerable help to the relevant authority responsible for initiating the competition, in this case the Senator for Building and Housing, Civil Engineering Department, Bridge Section, Berlin.

\section{White Concrete Kerbs and Marginal Strips}

Good white paving concrete fulfils a number of exacting requirements in the general scheme of concrete highway construction. Particularly is this the case where efficient and lasting white concrete directional carriageway markings are concerned, such as marginal strips and slabs, blocks with or without reflecting faces, kerbs, and other forms of contrasted paving. Behaviour under wet conditions at night is an important test of the officiency of white concrete, and the many methods, likewise the use of suitable materials available in different countries, are usually controlled by sensible and practical specifications. An article by $B$. Henk $\dagger$ doals with the precautions to be taken for enhancing the quality, the lightness of colour, and visual efficiency of white concrete for road-markings. * Cement and Concrete Association. Translation. No. 103: The
schmargendorf Flyover in Berlin : a Prestressed Concrete Bridge wilh Shell-like structural Action. By H. Heusel. (A translation of the article in German that appeared in Beton-und Stahl-betonbs\%, 55, No. 9, September 1960. Translation made by C. V. Amerognen.) Py. 21. (London: Cement and Corcrete Association, 1963.) $20 s$.

+ Cement and Concrete Association. Translation. No. 104: White concrete Kerbs and Marginal Strips. By B. Henk. (A translation of the article in German that appeared in Strassen- und 'l ieftau, 14, No. 9, September 1960. Translation made by C. V. Amerognen.) Pp. 22. (London: Cement and Concrete Association, 1963.) $20 s$.
Marginal strips both on single and dual conerote earriageways are normally relatively lightly trafficked. Even so, the constituents of the concrete which decisively affect the lightness of the colour are the cement, the white pigment solected, the sand, which must have the lightest possible colour and be at least in the particle-size range of less than $1 \mathrm{~mm}$. In this article the possibility of addition of white limestone sand is mentioned; the suggestion is also put forward that ". . . where very light colour is required in combination with a particularly high resistance to wear, it is advisable to add clean ealeined flint of $0-3 \mathrm{~mm}$ size to the mix". This applies especially to pedestrian crossings. The use of white cement is of paramount importance; ordinary grey cement is 'hungry' and uneconomic in use of pigment which evon with excess of the latter tends to remain much less light in colvur, especially in wet weather. White pigment is usually based on titanium oxide and zinc sulphide and normally constitutes between 3 and 5 per cent of the weight of the cement used. It is claimed that, adhering to these criteria, substantial advantages in the way of optical guidance, particularly under wet conditions, may be realized.

\section{Surface Regularity in the Construction of Concrete Roads}

This subject is presumably the aim of all civil engineers concerned with the construction of motorways in concrete wherever it may be. The keynote here is the regularity of the riding surface. This has nothing to do with nonskid surfacing as such, although this factor must be ideally the end in view in design of modern. State highways, autobahns, or expressways, in whatever country is involved. In the presont instance, the example comes from the motorways in Austria, where paramount importance is attached to the regularity of the surfaceprofile. There is much to be learnt in this connexion from a paper by J. Daum, read before the International Symposium of the Allg. Baumaschinen-Gesellschaft Hameln at Bad Neinberg in February $1961+$.

According to this author, riding surface has been improved by the use of obliquely functioning smoothing equipment, and to attain this the prerequisites "are the use of a concrete suitable for levelling and smoothing, and perfectly accurate positioning of the rails". Perhaps as important, if not more so, is the stress laid in this paper on the use of planographic control. Apart from technical considerations of the quality of the concrete involved to achieve the desired result, which are discussed in this paper, it is the emphasis laid on measurements carried out with the planograph (a profilometer for recording road-surface features and checking regularity of that surface while under construction), which both by description and illustration is surcly convineing.

What is apparent from this paper is the contrast in results of surface riding finish in concrete roads deriving from the use of machines with vibrating beams and oblique smoothing sereed, as compared with rnachines with integral finishing screeds. "On plan this follow-on screed is placed at an angle of between $10^{\circ}$ and $15^{\circ}$ in relation to the transverse direction. With this type of equipment there is no need to alter the consistence of the concrete, and low water/cement ratios can quite suitably be omployed". Results of planographic tests are shown graphically, and

$\ddagger$ Cement and Concrete Association. Translation. No. 105: Concrete Technology and Measurement of Surface Regularity in the Construction "f Concrete Roads. By J. Daum. A translation of the article in German that appeared in strasse wid Autobahn, 12. No. ., Juse 1961. Transtation mad 1963.) $20 s$. 
the author states: "In a large number of places and over fairly long lengths the irregularities are within the range of only $1 \mathrm{~mm}$; irregularities ranging between about $1 \mathrm{~mm}$ and $2 \mathrm{~mm}$ occur only over very short distances, and irregularities in excess of $3 \mathrm{~mm}$ are hardly present at all". The argument is impressive, but as tho author of this paper is careful to add: ". . . causes of irregularity of the concrete surface must be sought both in the constructional technique employed, i.e. the machines and their operation, and in failure to comply with the technological conditions applicable to any concrete used for pavement construetion".

\section{PHYSICS AT EINDHOVEN}

$\mathrm{T}$ HE oldest section of the Philips Research Laboratories was built at Eindhoven in 1924 in what was then a quiet rural district, but to-day it is hemmed in by the Philips factories and is surrounded by a busy town environment. The conditions are no longer suitable for advanced research work, and in 1958 it was decided to replace the Laboratories by a complex of new buildings in better surroundings. A site of about 275 acres at Waalre, a few kilometros south of Eindhoven, was obtained and buildings to accommodate a staff of some 3,000 by 1970 are to be built. The complex is to consist of four sectors, each sector comprising one large laboratory block. a workshop, subsidiary buildings for special experiments, a reading room, lecture theatre and canteen. There will be, in addition, at the centre of the site a building containing offices and general services, including a large restaurant, a central library and a spacious auditorium, suitable for large meetings and congresses. The laboratory block of the first sector has been completed and was recently taken into service. To mark the oceasion a symposium attended by a large number of distinguished guests representing research establishments in many countries was held at Waalre during September 26-27. Three main lectures wero given and fifty papers on specialized topies were read by members of the staff of the Laboratories.

The September issue of the Philips Technical Review $(24$, No. $11 / 12 ; 1963)$ is devoted to a description of the symposium, together with a photograph of the main eight-storey laboratory block and a descriptive article by M. J. Jansen Gration of the planning of the new complex of buildings. Prof. H. B. G. Casimir, the director of all the research activities of the Philips industries, gave a brief introductory address, and delivered the first lecture, entitled "Some Main Lines of 50 Years of Philips Research in Physics", in which he briefly reviewed various subjects of research at the Laboratories relating to gas discharges, ferromagnetism, solid-state physics and network theory. F. de Jager, in his lecture on "Modulation, Yesterday and Tomorrow", described how the everincreasing demands on communication links have led to the introduction of new methods of modulation. Frequency modulation, pulse-code modulation and delta modulation are discussed and, looking into the future, de Jager considered that during the next fifty years the combination of results found in information theory and in perception research will lead to the design of still more effective methods of modulation. The contributions of the Philips Research Laboratories to solid-state chemistry was the subject of the third main lecture, and $H$. J Vink briefly reviewed four areas of activity-crystal chemistry, internal charge compensation, gases and metals, and thermodynamies.

In addition to the texts of these talks, the Review contains summaries of the papers, and of the two demonstrations set up in the Laboratories. The papers are classified under four headings-fundamental, devices and materials, systems and measuring, and biochemistry and perception. The two demonstrations are of particular interest. The first, by $\mathrm{G}$. Prast, showed the recent application of a modification of the Philips-Stirling thermodynamic cycle which has enabled the production of a gas-refrigerating machine for the temperature of liquid hydrogen*. The addition of a Joule-Thomson circuit can extend the temperature range towards the helium region. The second demonstration, by E. F. de Haan and S. L. Tan, was of the 'Plumbicon', a pick-up tube similar to the 'Vidicon', but using the photoconductive properties of lead monoxide. A colour camera for television broadcasting using this tube has been constructed and is claimed to be four times more sensitive than a 3 -in. image 'Orthicon' colour eamera, with an improved signal-tonoise ratio and a higher range of contrast.

\section{S. WeINTROUB}

* A more detailed description has now been published in Cryogenics, 3 156 . September 1963.

\section{CARBIDES IN NUCLEAR ENERGY}

\begin{abstract}
$\mathrm{T}$ WO hundred and fifty delegates from eighteen countries attended a symposium held at the United Kingdom Atomic Energy Research Establishment, Harwell, during November $5-7$, at which sixty-seven papers were presented, dealing with many diverse aspects of the carbides of uranium, plutonium and thorium. The papers were divided into four separate sections, which were concerned with phase diagrams (Sessions 1 and 2), fabrication (Sessions 3 and 4), chemical and physical properties (Session 5), and irradiation behaviour (Session 6).

In the first two sessions, the earlier papers were concerned with features of the uranium-carbon diagram, the exact form of which remains in doubt. It was suggested by Magnier and Accary, of Saclay, that the shape of the uranium-rich boundary of the UC phase implies the existence of a phase of higher uranium content than UC. There seems to be little direct experimental evidence for this new phase, and some contributors to the discussion
\end{abstract}

were not convinced of its existence. Two papers dealt with the orientation relationships between $\mathrm{UC}_{2}$ and a parent UC matrix as determined by X-ray diffraction and electron diffraction and microscopy; the results were in good agreement. Imoto has shown that the hightemperature form of uranium dicarbide only exists for a carbon/uranium ratio less than $1 \cdot 86$, whereas the lowtemperature tetragonal form probably exists at the stoichiometric ratio.

Papers on plutonium-carbon alloys tended to confirm earlier work on the plutonium-carbon phase diagram and on the rate of self-irradiation damage of the various plutonium carbides; the complex behaviour of alloys with carbon contents between 40 and 50 atomic per cent, where $\mathrm{Pu}_{3} \mathrm{C}_{2}$ and $\mathrm{PuC}_{1-x}$ coexist, was also emphasized. Work on the uranium-plutonium-carbon system at carbon contents above $\mathbf{5 0}$ atomic per cent was described by Dalton, who has shown that the $M_{2} \mathrm{C}_{3}$ phase is rapidly 